\title{
高 KOEFICIJENT LEVERIDŽA KAO BAZELSKI STANDARD U FINANSIJSKOM UPRAVLJANJU NAFTNIH KOMPANIJA
}

\author{
Biljana P. Ivanova \\ Univerzitet odbrane u Beogradu \\ Lidija Barjaktarović, Ilija Đ. Ivanov \\ Univerzitet Singidunum, Beograd
}

Dredmet ovog rada je finansijska leveridž analiza kompanija u periodu od 2012. do 2016. godine, koje posluju u naftnoj industriji u Republici Srbiji (NIS a.d. Novi Sad, Lukoil Srbija d.o.o. Beograd i OMV Srbija d.o.o. Beograd). Leveridž analiza kao mera rizika bila je razmatrana od strane Bazelskog komiteta. Koeficijent leveridža ugrađenog u Bazel III jednostavan je za primenu pošto se lako izračunava, transparentan je, a najbitnije je da ukazuje na odnos između veličine kapitala banke i veličine izloženosti riziku, odnosno, kredibilna je mera koja ukazuje koliki su zahtevi za kapitalom. Osnov analize su finansijskih izveštaji odabranih kompanija javno obelodanjeni na sajtu Agencije za privredne registre. Rezultati finansijske leveridž analize ukazuju da su analizirana preduzeća relativno uspešno odgovorila na promene cene nafte i naftnih derivata na svetskom tržištu. Buduća istraživanja će razmotriti uspešnost upravljanja drugim tržišnim rizicima (kao što su: rizik konkurencije, devizni i kamatni rizik) u poslovanju kompanija u naftnoj industriji u Republici Srbiji.

Ključne reči: upravljanje, leveridž analiza, rizik, naftne kompanije

Uvod

Uloga finansijskog menadžmenta u bankarskom sektoru povećava se sa povećanjem značaja upravljanja rizicima. Fokus finansijskog menadžmenta se menja sa obezbeđivanja dovoljno sredstava za održavanje likvidnosti i solventnosti, na definisanje i obezbeđivanje visine nivoa kapitala u odnosu na potencijalne rizike. Svetsko tržište kapitala i novca pratile su velike i različite promene, te su iz tog razloga regulatorne institucije na svetskom nivou inicirale razvoj standarda kojima se upravlja rizikom kod svih institucija, kako finansijskih, tako i ne finansijskih. Banke imaju višestruke obaveze, a njena osnovna delatnost je kreditno-depozitna. Upravljanje rizicima i prinosom je njena osnovna funkcija. Obaveze banke odnose se na centralnu banku, ali i na njene dužnike, gde vrši procenu rizika prema međunarodnim standardima, iako je i sama pod lupom svih zainteresovanih strana na tržištu.

Preduzeća imaju različite finansijske potrebe u svom poslovanju, a banka ostvaruje svoju zaradu upravo zadovoljavajući njihove zahteve. Uticaj Potpisivanja Bazelskih sporazuma I, II i III, kao i promene koje su proistekle njihovom implementacijom odnosi se i 
na poslovanje privrednih subjekata koji su u obavezi da bankama daju mnogo više podataka prilikom podnošenja zahteva za kredit. Cilja ovog rada je da analizira i ukaže na poslovanja naftnih kompanija NIS, OMV, LUKOIL, koje su prema Nacionalnom naftnom komitetu Srbije, po uspešnosti poslovanja, bile rangirane kao prve tri u Srbiji u 2017. godini. Korišteni su finansijski izveštaji za period od 2012-2016. godine iz Agencije za privredne registre, kao i godišnji izveštaji kompanija koji su bili dostupni u 2017. godini. Analizom finansijskih i operativnih pokazatelja može se doći do odgovora na pitanja da li preduzeće ostvaruje adekvatnu zaradu, da li efikasno koristi raspoloživa sredstva, da li preduzeće može da ispuni svoje obaveze na vreme prema zainteresovanim stranama. Zainteresovani subjekti za ove odgovore mogu biti kreditori, investitori, akcionari, pravna, ali i fizička lica koja se mogu naći

\section{Finansijska leveridž analiza}

Prema Bazelu III, koeficijent leveridža je odnos između mere kapitala i mere ukupne izloženosti. Bazelski komitet je predložio minimalni nivo 1 koeficijenta leveridža od 3\%, a monitorning se vrši od strane Bazelskog komiteta na polugodišnjoj osnovi. (Barjaktarović, 2013)

Kako je naznačeno na sajtu Narodne banke Srbije, najznačajnije novine predviđene Bazel III standardima odnose se na:

- unapređenje kvaliteta kapitala i jačanje kapitalnih zahteva;

- uvođenje minimalnih standarda za upravljanje rizikom likvidnosti, kao i minimalnih pokazatelja likvidnosti;

- poboljšanje procesa upravljanja rizicima u cilju odgovarajućeg pokrića svih rizika kapitalom;

- uvođenje leveridž racija kao dodatnog pokazatelja poslovanja banaka koji nije zasnovan na stepenu rizičnosti aktive;

- uvođenje niza mera u cilju formiranja što adekvatnijih rezervi kapitala (capital buffers) koje bi bile raspoložive u periodima krize.

Ispravna ocena finansijskog položaja preduzeća postiže se istraživanjem odnosa između pozicija u bilansima stanja i uspeha, kao i u izveštajima o tokovima gotovine. Kvantificiranjem i istraživanjem tih odnosa bavi se analiza finansijskih izveštaja, a realizacija se obezbeđuje korišćenjem određenih instrumenata, odnosno, tehnika analize. (Malešević, 2011)

Knežević (2007) u analizi finansijskih izveštaja koristi sledeće instrumente:

- horizontalna analiza,

- vertikalna analiza,

- analiza osnovnih finansijskih indikatora (pokazatelja),

- analiza pomoću neto obrtnog fonda i

- analiza leveridža.

Pojam rizika predstavlja neizvesnost u pogledu očekivanog ishoda poslovne dobiti (poslovni rizik), odnosno neto dobiti (finansijski rizik). Njihovo zajedničko dejstvo čini totalni ili složeni rizik. U cilju upravljanja rizicima, kompanije se na različite načine trude da predvide rizike i od njih zaštite svoje poslovanje. 


\section{Faktor poslovnog leveridža}

Poslovni rizik (leveridž) pokazuje promene poslovnog dobitka u odnosu na promene prihoda od realizacije, odnosno obima prodaje. Nastaje svaki put kada preduzeće ima fiksne troškove koji ostaju nepromenjeni u apsolutnom iznosu bez obzira na kratkoročne fluktuacije u obimu prodaje. Dejstvo poslovnog leveridža odnosi se na kratak rok, jer su u dužem roku svi troškovi uglavnom varijabilni. Varijabilni troškovi direktno su uslovljeni ostvarenim obimom prodaje. Fiksni troškovi variraju u obrnutoj srazmeri sa promenama obima prodaje (Vasić, 2016).

Veći obim i prihodi od prodaje - manja opterećenost fiksnim troškovima - veći poslovni dobitak. Manji obim i prihodi od prodaje - veća opterećenost fiksnim troškovima manji poslovni dobitak. Ovo ima za posledicu da se poslovni dobitak, uz konstantnost ostalih faktora, menja jačim intenzitetom, nego što se menja prihod od prodaje.

Kako je poslovni rizik neizvesnost očekivane poslovne dobiti (EBIT), suštinu njegovog dejstva čine fiksni troškovi poslovanja, koji nisu uslovljeni promenama cena, visine prihoda i drugim uticajima.

Kompanija sa višim fiksnim troškovima nosi veći poslovni rizik, a s obzirom na to što se amortizacija uključuje kao fiksni trošak, potrebno je obratiti pažnju na kompanije sa visokim pozicijama osnovnih sredstava.

U cilju matematičkog izražavanja rizika koristimo faktor poslovnog leveridža, koji predstavljamo formulom (Mishkin, 2006):

$$
\text { Faktor poslovnog leveridža }=\frac{\text { Bruto marža (Gross margine) }}{\text { Poslovna dobit (EBIT) }}
$$

Sledeća formula faktora poslovnog leveridža može da obezbedi pokazatelj koliko promena poslovanja može da utiče na poslovnu dobit, jer mali pad prodaje, odnosno vrednosti bruto marže, može dovesti do drastičnog smanjenja poslovne dobiti.

$$
\text { Faktor poslovnog leveridža }=\frac{\text { Promena Bruto marže }}{\text { Promena prihoda od prodaje (Net Sales) }}
$$

To znači, ako se prihod prodaje poveća ili smanji za 1\%, poslovna dobit će se povećati ili smanjiti za onoliko \% koliko iznosi faktor poslovnog leveridža.

Tabela 1 - Faktor poslovnog leveridža analiziranih kompanija

\begin{tabular}{|l|r|r|r|r|r|}
\hline Lukoil & $\mathbf{2 0 1 2}$ & $\mathbf{2 0 1 3}$ & $\mathbf{2 0 1 4}$ & $\mathbf{2 0 1 5 .}$ & $\mathbf{2 0 1 6 .}$ \\
\hline \hline Bruto marža & $3,084,082$ & $2,548,584$ & $2,568,441$ & $2,682,464$ & $2,622,743$ \\
Poslovna dobit & $-697,196$ & $-2,559,615$ & $-11,162,246$ & 358,986 & $1,815,779$ \\
\hline Faktor poslovnog leveridža & $-\mathbf{0 . 2}$ & $\mathbf{- 1 . 0}$ & $\mathbf{- 4 . 3}$ & $\mathbf{0 . 1}$ & $\mathbf{0 . 7}$ \\
\hline \hline & & & & & \\
\hline OMV & $\mathbf{2 0 1 2}$ & $\mathbf{2 0 1 3}$ & $\mathbf{2 0 1 4}$ & $\mathbf{2 0 1 5 .}$ & $\mathbf{2 0 1 6 .}$ \\
\hline \hline Bruto marža & $3,605,640$ & $3,421,582$ & $3,458,110$ & $3,917,700$ & $3,745,904$ \\
Poslovna dobit & 308,322 & $-605,476$ & $-1,364,257$ & 947,637 & 871,339 \\
\hline Faktor poslovnog leveridža & $\mathbf{1 1 . 7}$ & $\mathbf{- 5 . 7}$ & $\mathbf{- 2 . 5}$ & $\mathbf{4 . 1}$ & $\mathbf{4 . 3}$ \\
\hline \hline
\end{tabular}




\begin{tabular}{|l|r|r|r|r|r|} 
& & & & & \\
\hline NIS & $\mathbf{2 0 1 2}$ & $\mathbf{2 0 1 3}$ & $\mathbf{2 0 1 4}$ & $\mathbf{2 0 1 5}$. & $\mathbf{2 0 1 6 .}$ \\
\hline \hline Bruto marža & $113,222,032$ & $107,516,893$ & $102,327,142$ & $77,780,532$ & $71,355,174$ \\
Poslovna dobit & $56,984,850$ & $53,162,763$ & $47,480,277$ & $30,689,530$ & $23,245,271$ \\
\hline Faktor poslovnog leveridža & $\mathbf{2 . 0}$ & $\mathbf{2 . 0}$ & $\mathbf{2 . 2}$ & $\mathbf{2 . 5}$ & $\mathbf{3 . 1}$ \\
\hline \hline & & & & & \\
\hline prihodi od prodaje & $\mathbf{2 0 1 2}$ & $\mathbf{2 0 1 3}$ & $\mathbf{2 0 1 4}$ & $\mathbf{2 0 1 5}$ & $\mathbf{2 0 1 6 .}$ \\
\hline \hline Lukoil & $45,302,952$ & $30,347,465$ & $28,814,513$ & $31,726,482$ & $29,087,265$ \\
OMV & $38,223,907$ & $31,075,305$ & $31,154,253$ & $31,920,818$ & $28,132,967$ \\
NIS & $230,070,824$ & $252,577,047$ & $247,620,582$ & $199,861,276$ & $177,913,601$ \\
\hline
\end{tabular}

Tabela 2 - Pojedinačni prikaz faktora poslovnog leveridža analiziranih kompanija

\begin{tabular}{|l|r|r|r|}
\hline Lukoil & pr.od prodaje & posl.dobit & leveridž \\
\hline \hline 2012. & $45,302,952$ & $-697,196$ & -0.2 \\
2013. & $30,347,465$ & $-2,559,615$ & -1.0 \\
2014. & $28,814,513$ & $-11,162,246$ & -4.3 \\
2015. & $31,726,482$ & 358,986 & 0.1 \\
2016. & $29,087,265$ & $1,815,779$ & 0.7 \\
\hline OMV & pr.od prodaje & posl.dob & leveridž \\
\hline \hline 2012. & $38,223,907$ & 308,322 & 11.7 \\
2013. & $31,075,305$ & $-605,476$ & -5.7 \\
2014. & $31,154,253$ & $-1,364,257$ & -2.5 \\
2015. & $31,920,818$ & 947,637 & 4.1 \\
2016. & $28,132,967$ & 871,339 & 4.3 \\
\hline NIS & pr.od prodaje & posl.dob & leveridž \\
\hline \hline 2012. & $230,070,824$ & $56,984,850$ & 2.0 \\
2013. & $252,577,047$ & $53,162,763$ & 2.0 \\
2014. & $247,620,582$ & $47,480,277$ & 2.2 \\
2015. & $199,861,276$ & $30,689,530$ & 2.5 \\
2016. & $177,913,601$ & $23,245,271$ & 3.1 \\
\hline
\end{tabular}

Prema podacima iz tabela 1, 2 i 3, možemo zaključiti da sve tri prikazane kompanije, bez obzira na evidentni pad prihoda od prodaje, kao i smanjenje poslovne dobiti u 2016. godini, ostvaruje uvećan faktor poslovnog leveridža, što ukazuje na efektivnije upravljanje fiksnim troškovima. 
Osim kompanije NIS koja i u ranijim godinama ostvarivala isti ovaj efekat, druge dve kompanije su pokazivale fluktuaciju faktora poslovnog leveridža, usled nestabilizovanog odnosa prihoda i poslovne dobiti. Očito je da kompanije pokušavaju da utiču na svoje fiksne troškove na šta upućuje i podatak o rapidnom smanjenju broja zaposlenih tokom prikazanih godina, kao i evidentirane prodaje fiksnih sredstava.

Tabela 3 - Komparativni prikaz faktora poslovnog leveridža analiziranih kompanija

\begin{tabular}{|l|r|r|r|r|r|}
\hline \multicolumn{1}{|c|}{$\begin{array}{c}\text { Faktor poslovnog } \\
\text { leveridža }\end{array}$} & \multicolumn{1}{c|}{ 2012. } & \multicolumn{1}{c|}{ 2013. } & \multicolumn{1}{c|}{ 2014. } & \multicolumn{1}{c|}{ 2015. } & \multicolumn{1}{c|}{ 2016. } \\
\hline \hline Lukoil & -0.2 & -1.0 & -4.3 & 0.1 & 0.7 \\
\hline OMV & 11.7 & -5.7 & -2.5 & 4.1 & 4.3 \\
\hline NIS & 2.0 & 2.0 & 2.2 & 2.5 & 3.1 \\
\hline
\end{tabular}

Zaključujemo da faktor poslovnog leveridža, kao pokazatelj rizika, treba da bude viši od 0 , dok njegova stabilnost, uočena kroz godine, ukazuje na stabilno poslovanje. Takođe, izuzetno visok Faktor poslovnog leveriža predstavlja izuzetno visok rizik, jer će ukazati da će i sa najmanjim smanjenjem prihoda od poslovanja doći do dramatičnog smanjenja poslovne dobiti.

\section{Faktor finansijskog leveridža}

Finansijski rizik predstavlja neizvesnost očekivane neto dobiti, te suštinu njegovog dejstva čine fiksni rashodi finansiranja, koji nisu uslovljeni promenama poslovne dobiti. Fiksnim rashodima finansiranja se obuhvataju rashodi na ime kamata, proistekli iz različitih vidova zaduživanja. Finansijski rizik matematički možemo predstaviti faktorom finansijskog leveridža, kojeg čini odnos poslovne dobiti (EBIT) i dobit pre oporezivanja (EBT) (Živković i dr., 2012):

$$
\text { Faktor finansijskog leveridža }=\frac{\text { Poslovna dobit }(E B I T)}{\text { Dobit pre oporezivanja }(E B T)}
$$

Sledeća formula faktora finansijskog leveridža pokazuje koliko promena u visini poslovne dobiti može da utiče na dobit pre oporezivanja. U tom smislu, faktor finansijskog leveridža određuje rizik koji prouzrokuju kamate, kao fiksni trošak kompanije, te time treba da utiče na odgovarajuće odluke po pitanju nivoa i načina finansiranja.

Faktor finansijskog leveridža $=\frac{\text { Promena dobiti pre oporezivanja }(E B T) \%}{\text { Promena poslovne dobiti }(\text { EBIT }) \%}$ 
Tabela 4 - Pojedinačni prikaz faktora finansijskog leveridža analiziranih kompanija

\begin{tabular}{|l|r|r|r|}
\hline Lukoil & Dobit pre opor. & posl.dobit & \multicolumn{1}{|c|}{ leveridž } \\
\hline \hline 2012 & $-2,817,359$ & $-697,196$ & 0.2 \\
2013 & $-3,152,409$ & $-2,559,615$ & 0.8 \\
2014 & $-14,187,058$ & $-11,162,246$ & 0.8 \\
2015 & $-1,091,119$ & 358,986 & -0.3 \\
2016 & 801,514 & $1,815,779$ & 2.3 \\
\hline OMV & Dobit pre opor. & posl.dob & leveridž \\
\hline \hline 2012 & $-641,128$ & 308,322 & -0.5 \\
2013 & $-626,566$ & $-605,476$ & 1.0 \\
2014 & $-1,528,342$ & $-1,364,257$ & 0.9 \\
2015 & 842,174 & 947,637 & 1.1 \\
2016 & 757,561 & 871,339 & 1.2 \\
\hline NIS & & posl.dob & leveridž \\
\hline \hline 2012 & Dobit pre opor. & $56,984,850$ & 1.1 \\
2013 & $51,324,959$ & $53,162,763$ & 0.9 \\
2014 & $58,309,328$ & $47,480,277$ & 1.3 \\
2015 & $36,456,884$ & $30,689,530$ & 1.5 \\
2016 & $20,455,884$ & $23,245,271$ & 1.2 \\
\hline
\end{tabular}

Tabela 5 - Faktor finansijskog leveridža analiziranih kompanija

\begin{tabular}{|c|c|c|c|c|c|}
\hline Lukoil & 2012 & 2013 & 2014 & 2015 & 2016 \\
\hline Dobit pre oporezivanja & $-2,817,359$ & $-3,152,409$ & $-14,187,058$ & $-1,091,119$ & 801,514 \\
\hline Poslovna dobit & $-697,196$ & $-2,559,615$ & $-11,162,246$ & 358,986 & $1,815,779$ \\
\hline Faktor finansijskog leveridža & 0.2 & 0.8 & 0.8 & -0.3 & 2.3 \\
\hline OMV & 2012 & 2013 & 2014 & 2015 & 2016 \\
\hline Dobit pre oporezivanja & $-641,128$ & $-626,566$ & $-1,528,342$ & 842,174 & 757,561 \\
\hline Poslovna dobit & 308,322 & $-605,476$ & $-1,364,257$ & 947,637 & 871,339 \\
\hline Faktor finansijskog leveridža & -0.5 & 1.0 & 0.9 & 1.1 & 1.2 \\
\hline NIS & 2012 & 2013 & 2014 & 2015 & 2016 \\
\hline Dobit pre oporezivanja & $51,324,959$ & $58,309,328$ & $36,456,884$ & $20,455,884$ & $18,601,544$ \\
\hline Poslovna dobit & $56,984,850$ & $53,162,763$ & $47,480,277$ & $30,689,530$ & $23,245,271$ \\
\hline Faktor finansijskog leveridža & 1.1 & 0.9 & 1.3 & 1.5 & 1.2 \\
\hline
\end{tabular}


Prema podacima iz tabela 4, 5 i 6 može se uočiti da što je viši faktor finansijskog leveridža ukazuje na veću zaduženost kompanija, dok faktor ispod 1 treba da ukazuje da kompanija ima prihod od finansijskog poslovanja, kao što je slučaj u kompaniji NIS 2013. godine.

Međutim, treba biti obazriv prilikom ovakvog tumačenja faktora finansijskog leveridža i uzeti u obzir da će se faktor niži od 1 pokazati i u slučajevima kada kompanija posluje sa gubitkom, kao što je slučaj kod kompanija LUKOIL i OMV.

Tabela 6 - Komparativni prikaz faktora poslovnog leveridža analiziranih kompanija

\begin{tabular}{|l|c|c|c|c|c|}
\hline \multicolumn{1}{|c|}{ Faktor finansijskog leveridža } & $\mathbf{2 0 1 2}$ & $\mathbf{2 0 1 3}$ & $\mathbf{2 0 1 4}$ & $\mathbf{2 0 1 5}$ & $\mathbf{2 0 1 6}$ \\
\hline \hline Lukoil & 0.2 & 0.8 & 0.8 & -0.3 & 2.3 \\
\hline OMV & -0.5 & 1.0 & 0.9 & 1.1 & 1.2 \\
\hline NIS & 1.1 & 0.9 & 1.3 & 1.5 & 1.2 \\
\hline
\end{tabular}

\section{Faktor totalnog leveridža}

Budući da je poslovni leveridž determinisan odnosom \% povećanja poslovnog dobitka u odnosu na \% porast obima prodaje, dok je finansijski leveridž determinisan odnosom \% povećanja neto dobitka u odnosu na \% povećanje poslovnog dobitka - oba dejstva leveridža reflektuju se na stopu prinosa na sopstvena sredstva (neto dobitak / sopstveni kapital). Kumuliranjem oba leveridža dobija se tzv. totalni leveridž koji odražava izloženost preduzeća ukupnom ili totalnom riziku.

Složeno dejstvo poslovnog i finansijskog leveridža analizira se u granicama očekivanih oscilacija prihoda od prodaje prema donjoj granici rentabilnosti. Ovo posebno važi za tzv. kapitalno intenzivna preduzeća koja se odlikuju visokim učešćem fiksnih troškova u ukupnim troškovima i gde visok faktor poslovnog leveridža obezbeđuje srazmerno velike promene poslovnog dobitka na bazi relativno malih oscilacija u obimu prodaje. Totalni leveridž pojavljuje se kao neizvesnost pri ostvarivanju bruto dobitka, neto dobitka i prinosa na sopstveni kapital. Sveukupan rizik pred kojim se nalazi preduzeće.

Kod kompanija koje su izložene i fiksnim poslovnim i fiksnim finansijskim rashodima uzimamo u obzir faktor totalnog leveridža (tabela 7), s obzirom na to što su takve kompanije dvostruko izložene riziku. One ispoljavaju kumulativni rizik neizvesnosti na očekivanu neto dobit, gde se promenama u obimu aktivnosti povećava rizik pokrića i poslovnih i finansijskih obaveza.

Faktor totalnog leveridža je izražen kao proizvod poslovnog i finansijskog leveridža:

Faktor totalnog leveridža = Faktor poslovnog leveridža $x$ Faktor finansijskog leveridža

Tabela 7 - Faktor totalnog leveridža analiziranih kompanija

\begin{tabular}{|c|c|c|c|}
\hline Faktor totalnog leveridža & Lukoil & OMV & NIS \\
\hline \hline 2012 & -0.06 & -5.62 & 2.21 \\
\hline 2013 & -0.82 & -5.46 & 1.84 \\
\hline 2014 & -3.42 & -2.26 & 2.81 \\
\hline 2015 & -0.04 & 4.65 & 3.80 \\
\hline 2016 & 1.57 & 4.94 & 3.84 \\
\hline
\end{tabular}


Barjaktarović (2013) naglašava da racio brojevi ne daju odgovore, već samo ukazuju na pitanja koja treba postaviti.

Veoma je važno prilikom analiziranja dobijenih rezultata povezati stopu prinosa na vlasnički kapital (ROE, SPSK), stopu prinosa na ukupna ulaganja (SPUS*) i prosečnu kamatnu stopu. Ovo je bitno jer se negativan efekat finansijskog leveridža ispoljava na sledeći način: Ako je prosečna kamatna stopa veća od SPUS*, SPSK strmoglavo opada, manja je od SPUS što je nepovoljno za preduzeće, koje treba da smanji nivo zaduženosti. Ali, pogrešno je reći da SPSK postaje negativna veličina. Ukoliko je prisutan pozitivan efekat finansijskog leveridža, on se očitava u tome da raste rentabilnost vlasničkog kapitala, tj. raste SPSK, najpre sporije pa brže. SPUS* > k; SPSK > SPUS.

\section{Zaključak}

Finansijska analiza ime veliki značaj jer je namenjena da približi i olakša investicione odluke mnogobrojnim profesionalnim investitorima, ali i mnogobrojnim individualnim. Svaki investitor treba da bude veoma oprezan kod finansijskih analiza u cilju minimiziranja rizika. Usled uticaja internih i eksternih faktora, isti racio broj može dati različite vrednosti kod promena u poslovanju. Određeni pokazatelj se različito tumači ako se gleda jedna ili više godina, ali je bitno i poređenje sa liderom u grani, sa konkurentom i sl. Na osnovu kombinacije uzetih racia za analiziranje, ukoliko se uporede sa istim pokazateljima iz prethodnih godina može se izvesti zaključak o razvojnom trendu preduzeća. Slično tome, ako se uporede sa koeficijentima drugih preduzeća, može se sagledati položaj preduzeća u odnosu na konkurenciju. Zaključak sprovedene analize ukazuje da su analizirana preduzeća uspešno odgovorila na izazove kretanja cene nafte i naftnih derivata u prethodnom periodu. Možemo zaključiti da sve tri prikazane kompanije, bez obzira na evidentni pad prihoda od prodaje, kao i smanjenje poslovne dobiti u 2016. godini, ostvaruju uvećan faktor poslovnog leveridža, što ukazuje na efektivnije upravljanje fiksnim troškovima. Dalje se može uočiti da što je viši faktor finansijskog leveridža ukazuje na veću zaduženost kompanija, dok faktor ispod 1 treba da ukazuje da kompanija ima prihod od finansijskog poslovanja, kao što je slučaj u kompaniji NIS 2013. godine.

Buduća istraživanja će uključiti u analizu uspešnost upravljanja drugim tržišnim rizicima, kao što je rizik konkurencije, devizni i kamatni rizik. Ali, pre svega, pouzdanost zaključivanja na osnovu finansijske leveridž analize zavisi od pouzdanosti podataka na osnovu kojih su izračunati, kao i da samo sveobuhvatno posmatranje može dati ispravan prikaz uspešnosti poslovanja preduzeća.

\section{Literatura}

[1] Barjaktarović L., (2013), Upravljanje rizikom, Univerzitet Singidunum, Beograd

[2] Barjaktarović S., (2006), Investiciono bankarstvo i tržište hartija od vrednosti, Zadužbina Andrejević, Beograd

[3] Bikker J.A., (2004), Competition and efficiency in a unified European banking market, Edward Elgar Publishing, Cheltenham

[4] Knežević G., (2007), Ekonomsko-finansijska analiza, Univerzitet Singidunum, Beograd 
[5] Lipczynski J., Wilson J., (2001), Industrial Organisation- An Analysis of Competitive Markets, Prentice Hall, Harlow

[6] Milojević, I., Vukoje, A., Mihajlović, M.,(2013) Accounting consolidation of the balance by the acquisition method, Ekonomika poljoprivrede, Vol. 60, No2, str. 237-252, ISSN: 0352-3462, UDC: 657.375 .6

[7] Mihajlović M. (2016) Odnos menadžmenta preduzeća i korporativnog upravljanja, ODITOR, 1 (2), str. 4-10.

[8] Mishkin S., (2006), Monetarna ekonomija, bankarstvo i finansijska tržišta- sedmo izdanje, Data status, Beograd

[9] Rose S.P., Hudging C.S., (2005), Bankarski menadžment i finansijske usluge, Data status, Beograd.

[10] Stanojević S, Đorđević N., Volf D. (2017) Primena kvantitativnih metoda u predviđanju poslovanja privrednih društava, ODITOR, 1 (3), str. 92-101.

[11] Živković A., Stankić R., Marinković S., (2012), Bankarsko poslovanje i platni promet, Ekonomski fakultet, Beograd.

[12] Malešević Z., (2011), Otvorenost finansijskog tržišta Republike Srbije za integraciju sa finansijskim tržištima zemalja EU, Škola biznisa, http://www.vps.ns.ac.rs/SB/2011/8.8.pdf, datum pristupa 13. mart 2018.

[13] Vasić J., (2016), Uticaj finansijskih tržišta na kvalitet makro-ekonomskih performansi Srbije i zemalja Centralne Evrope, doktorska disertacija,

http://nardus.mpn.gov.rs/bitstream/handle/123456789/8088/Disertacija.pdf?sequence=1\&isAllowed =y, datum pristupa 19. februar 2018.

[14] Nacionalni naftni komitet Srbije, (2016), Cena nafte i investicije u naftnoj industriji, Bilten br. 19.

[15] Nacionalni naftni komitet Srbije, (2017), Godina u svetu nafte i gasa-analize, vesti i stavovi, publikacija.

[16] Agencija za privredne registre, http://www.apr.gov.rs/, datum pristupa 18. januar 2018.

[17] FOREX, http://cena-nafte.com/, datum pristupa 24. januar 2018. godine

[18] LUKOIL Srbija, http://lukoil.rs/sr/About/ObligatoryInformationDisclosure, datum pristupa 18. januar 2018.

[19] Naftna industrija Srbije, https://www.nis.eu/lat/, datum pristupa 18. januar 2018.

[20] NYMEX, http://www.cmegroup.com/, datum pristupa 24. januar 2018. godine

[21] OMV Srbija, http://www.omv.co.rs/portal/01/rs/private, datum pristupa 18. januar 2018. 